\title{
Factors that Hinder Parents from the Communicating of Sexual Matters with Adolescents in Rwanda
}

\author{
Bushaija $\mathrm{E}^{1^{*}}$, Sunday $\mathrm{F} \mathrm{X}^{2}$, Asingizwe $\mathrm{D}^{2}$, Olayo $\mathrm{R}^{3}$, Abong’o $\mathrm{B}^{4}$ \\ ${ }^{1}$ Department of Clinical Medicine and Community Health, College of Medicine and Health Sciences, University of Rwanda \\ ${ }^{2}$ Directorate of Research, Ethics and Consultancy, College of Medicine and Health Sciences, University of Rwanda \\ ${ }^{3}$ Great lakes university of Kisumu, Tropical Institute of Community health and Development, Kenya \\ ${ }^{4}$ Great lakes university of Kisumu, Tropical Institute of Community health and Development, Kenya
}

\begin{abstract}
Parent-adolescent communication about sexual matters is one of the means that encourages adolescents to adopt responsible sexual behaviour. However, parents do not discuss sexual matters with adolescents and those who discuss to some extent; little information about sexuality is provided. This study, was, therefore aimed to find out the factors that hindered parents from communicating with their adolescent children on sexual matters. A descriptive, cross sectional study employing both quantitative and qualitative approaches was utilized. Simple random sampling was used to select households of parents/caretakers with adolescents and face to face interviews were used to collect data in February 2011. Out of 388 respondents, majority $(81 \%)$ reported that they do not discuss sexual matters with the adolescents due to socio-demographic, cultural, individual and socio-environmental factors/barriers. Being male $(\mathrm{p}=0.04)$, parents' age over 44 years $(\mathrm{OR}<1$ at $95 \% \mathrm{CI})$, lower levels of education ( $\leq$ primary) and income (farming and remittance) was significantly associated with "not communicating" sexual matters with the adolescents $(p<0.05)$. These findings strengthen the need for continued sensitization of parents/caretakers to involve themselves in discussing sexual matters with the adolescents. Furthermore, guidance of parents/caretakers on how to approach the subject of sexuality and sustenance of discussions with the adolescents is paramount.
\end{abstract}

Key words: Communication, Sexual matters, Parents/ Caretakers, Adolescents

\section{Introduction}

Communication of sexual matters between parents and adolescents is one of the strategies that could encourage adolescents to delay sexual debut or avoid unprotected sexual intercourse. [1-3] However, parents and their adolescent children do not often communicate about sexual matters, and even where discussions occur, parents provide scanty information about sexual matters. [1, 4]

There are efforts by the Government of Rwanda, partner institutions such as UNFPA, ARBEF, IMBUTO Foundation and media to promote the strategy of parent-adolescent communication. For example, a popular radio soap opera URUNANA [5] addresses sexuality issues which are culturally sensitive and encourages parent-adolescent communication among others. Similarly, are IMBUTO Foundation [6] initiatives on health that engage parents and young people in communication including reproductive health matters. Despite the efforts by these institutions, parents seem not to discuss sexual matters with their adolescent children. According to the National AIDS Control Programme, "Teenagers don't sometimes feel concerned to go for HIV voluntary testing and the most discouraging issue is that most parents don't want to talk to their children about sex relationships and other related matters". [7]
Many factors hinder parents from discussing sexual matters with their children such as lack of sexuality information. $[1,8,9]$ Parents may also be inhibited from discussing sexual matters with their children due to cultural taboos and beliefs. $[10,11]$ In most African tradition, the family and immediate community other than parents, provided adolescents with information and guidance about sexuality but these traditional channels of communication are almost non-existent today. [8] Studies [12-15] conducted in South America and Africa show that demographic factors such as gender of parents hinder discussions about sexuality with adolescents. For example, boys may receive little or no information from their parents and fathers communicate rarely over sexual matters with their children. A study in Ghana [10] found that some parents viewed discussions on sexual matters with adolescents as a means that could entice them to indulge in sexual intercourse. Other parents also perceive adolescents as too young to discuss sexual matters while others view adolescents as knowledgeable since they learn from the peers and media. [8]

In Rwanda, currently there is paucity of literature to elucidate the constraints to parent-adolescent communication about sexual matters. Besides, several studies outside Rwanda on sexuality involving adolescents are institution-based and few

*correspondence: Bushaija Emmy, Email: ebushaija@khi.ac.rw 
have been conducted in rural areas involving both parents and their adolescent children. The study therefore sought to find out the socio-demographic, cultural, individual and socioenvironmental factors that hindered parents from discussing sexual matters with adolescents in a rural community of the Eastern province in Rwanda. Parents are authoritative giving directives to adolescents who are expected to obey and listen. As a result, barriers are encountered which hinder communication of sexual messages between the parents and adolescents.

\section{Methodology}

The target population for the study was households of parents or caretakers with adolescents. The study was descriptive and cross-sectional in design which took both quantitative and qualitative approaches. Quantitative data was collected using a semi-structured questionnaire while topic guides were used for qualitative data. Eight Focus Group Discussions (FGDs) with parents/caretakers, four FGDs with adolescents and four Key informant interviews (KIIs) with local leaders were conducted. The FGDs were conducted with adolescents whose parents/caretakers had reported discussing sexual matters to verify if discussions took place. Qualitative data provided more in-depth understanding of the factors that hindered parents from communicating sexual matters with adolescents, taking into account the sensitive nature of the topic. The sample size was determined using the formula by Cochran [16] where the assumed prevalence of the problem was $50 \%$ (maximum variability) at the $95 \%$ confidence level of Z-score of 1.96 and margin error of 0.05 thus giving a minimum sample size of 384; but 388 was the final sample taken.

Probability and non-probability sampling methods were used. Purposive sampling was used to select the District, Sector and cells while $50 \%$ of villages (18 villages) were sampled in each cell using simple random sampling. At the village level, a sampling frame of parents/caretakers with adolescents was made and by using proportionate distribution, households of parents/caretakers with adolescents were picked randomly using lottery method without replacement, until the desired number of households for each village was obtained. The households were replaced during data collection by sampling the nearest household in case there was a need to balance gender, which gave equal number of males and females. Quality Control was ensured by seeking expert opinion from researchers and statisticians about the content and design of the research tools. The tools were also compared to others used in previously related studies, translated from English to Kinyarwanda and pre-tested in a non-study area. After pre-testing, the questions were revised and final copies in Kinyarwanda were produced for data collection. Five Research Assistants were trained in quantitative and qualitative interview techniques and the principal investigator inspected the collected data at the end of each day to ensure completeness, consistency and legibility. Missing data were identified and collected from the respective households on the following day.
The pre-coded data was checked and entered in the computer using EpiData version 3.1. Accuracy of data entered was further checked, cleaned through trial runs and quantitative data were exported from EpiData 3.1 to Stata SE version 10 for analysis. Univariate analysis of all variables using frequencies and percentages was first run. Then, knowledge variables were dichotomized into right or wrong responses and overall knowledge of respondents was categorized as good, fair or poor based on the number of correct responses of knowledge items about reproductive health. Good knowledge was referred as 7 to 10 correct responses; Fair knowledge referred to 4 to 6 correct responses while poor knowledge was 0 to 3 correct responses. On the other hand, the respondents' responses about negative attitudes towards adolescents' sexuality was categorized as disagreed, agreed or undecided about the attitude. Cross tabulations were done and Chi- square test at significance level of $5 \%$ was run to establish the relationship between the variables (socio-demographic, knowledge, attitude and communication outcome). Binary logistic regression was also used to determine the association between communication outcome and the ages of respondents.

For qualitative data, notes from FGDs and KII were edited manually after each discussion. Notes on the topics discussed and notes of non-verbal communication observed during FGDs was linked and summarized at the end of each session. Similar statements were identified and interpreted under categories labeled with a key word. Interpretation was done by identifying patterns and connections within and between categories following the major themes that corresponded to the specific objectives. Furthermore, quotations were identified and checked to see whether they appropriately fit in the categories and were reported narratively.

\section{Results}

A total of 388 participants took part in the study and comprised of parents $(71 \%)$ and caretakers (29\%). The mean age of parents/caretakers was 46 years with $10 \%$ in age range 25 to 29 years of whom the youngest was a female caretaker. The respondents were distributed equally by gender. Majority (81\%) of respondents did not communicate with the adolescents on sexual matters. The variation of respondents' age in relation to communication practice was statistically significant $(p=0.000)$; and $63 \%$ (Figure 1) of respondents that did not communicate with adolescents on sexual matters were aged over 44 years $(\mathrm{OR}<$ 1 at $95 \% \mathrm{CI}$ ). An elderly woman discussant said "It is difficult to introduce and discuss sexual topics with adolescents considering the age difference between myself and the child."

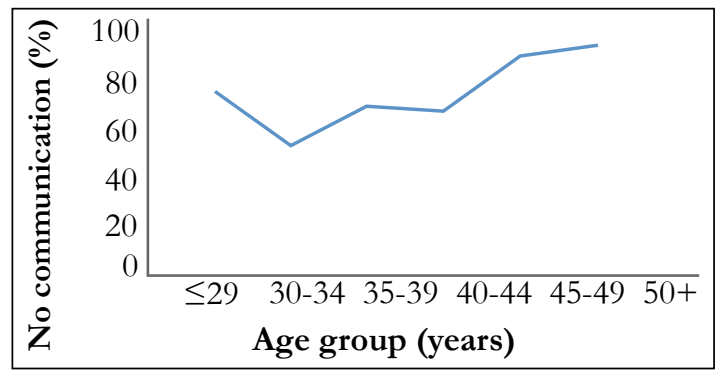

Figure 1 Ages of parents/caretakers by No communication practice 
Gender of respondents influenced communication with adolescents about sexual matters. About $53 \%$ of males did not discuss sexual matters compared to the females (47\%) and the difference was statistically significant $(\mathrm{p}=0.04)$. A male discussant said: "It is the mother's responsibility to discuss sexual matters with our adolescent children". Of the sub sample of 74 respondents that discussed sexual matters with adolescents, all male respondents (39\%) did so without preference of adolescents' gender. On the other hand, 19\% of female respondents preferred discussions with girls rather than boys and a female discussant said: "I prefer discussions with girls since boys do not worry us in matters of sexuality".

Education level of parents/caretakers was associated with communication practice and the odds of 'not communicating' sexual matters were higher among respondents with education level less or equal to primary than respondents with vocational education and above $(\mathrm{p}=0.000)$. However, one of the discussant with education above secondary level said: "I find it very difficult and wonder how to talk about sexual related topics with adolescents, yet I know the biology of reproduction".

Regarding Religious affiliation and respondents' communication practice, Table 1 shows that all respondents without a religious affiliation (5.7\%) did not discuss sexual matters with adolescents although the relationship of "not communicating" to affiliation to religion was not statistically significant $(\mathrm{p}=0.06)$.

Table 1 Religious affiliation of respondents and communication practice $\mathrm{N}=388$

\begin{tabular}{|c|c|c|c|}
\hline \multicolumn{4}{|c|}{ Communication practice } \\
\hline & Yes & No & Total \\
\hline Religion & $N(\%)$ & $N(\%)$ & $\mathrm{N}(\%)$ \\
\hline Anglican & $14(19)$ & $58(18.5)$ & $72(18.6)$ \\
\hline Catholic & $25(34)$ & $120(38.2)$ & $145(37.4)$ \\
\hline SDA & 14 (19) & $31(9.9)$ & $45(11.6)$ \\
\hline Muslim & $8(10.8)$ & $21(6.7)$ & $29(7.5)$ \\
\hline Pentecostal & $13(17.6)$ & $66(21)$ & $79(20.4)$ \\
\hline None & 000.00 & $18(5.7)$ & $18(4.6)$ \\
\hline Total & (19) & $314 \quad(81)$ & 388 (100) \\
\hline
\end{tabular}

Furthermore, $12 \%$ of the respondents that did not discuss sexual matters with adolescents attributed it to their religious belief as a major factor as one of the discussant said: "As a Christian, you cannot advise your adolescent child to use condoms which is immoral'.

The findings on parents/caretakers' income in relation to communication practice showed that respondents that depended on farming and remittances were less likely to discuss sexual matters than the salaried and self-employed $(\mathrm{p}=0.03)$.

Furthermore, 264 respondents attributed their low socioeconomic status as a factor that inhibited them from discussing sexual matters with adolescents, citing lack of time due to busy work schedule of the parent/caretaker (70\%) as a major hindrance. Other factors included lack of radio or television set $(22 \%)$ at home for sexuality information, busy schedule of adolescent (4\%) and lack of privacy (4\%) where discussions with children could be conducted. Cultural factors such as beliefs and taboos also hindered parents/ caretakers from discussing sexual matters with adolescents. Of the 314 parents/caretakers that did not discuss sexual matters with adolescents, $39 \%$ found it difficult to mention sexual terms in Kinyarwanda while others either had prohibitive beliefs or considered it a role of aunts and uncles as shown in Figure 2.

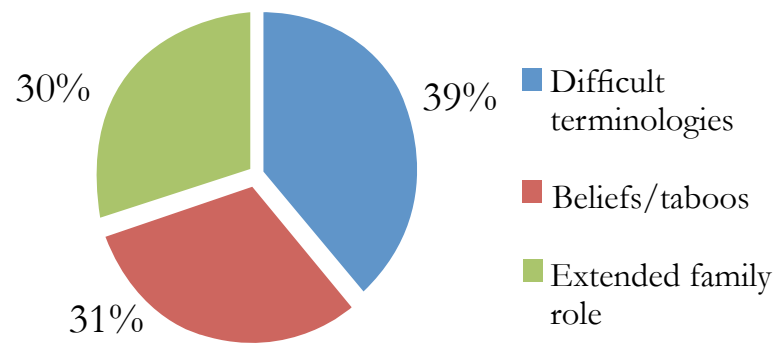

Figure 2 Cultural factors that hinder communication

Regarding individual factors (knowledge and attitudes) that hindered parents from communicating sexual matters with adolescents, lack of knowledge on sexual matters was a major factor of whom $55 \%$ found it difficult to respond to the child's questions, $26 \%$ had difficulty in introducing sexual topics while $19 \%$ attributed it to illiteracy. In support of this argument, one of the discussant said: " $M y$ children are more knowledgeable about sexual matters hence I do not know how I can advise them". The parents/caretakers' knowledge of reproductive health topics showed that, difference in knowledge between parents/caretakers that discussed and those that did not discuss with adolescents was statistically significant $(\mathrm{p}<0.05)$, although the overall knowledge of all respondents was mostly fair (43\%) as shown in Table 2.

Table 2 Overall knowledge of respondance on adolescent sexual matters $(\mathrm{N}=388)$

\begin{tabular}{lccc}
\hline \multicolumn{4}{c}{ Communication Practice } \\
\hline Yes & No & Total \\
\hline Good Knowledge & $39(53)$ & $44(14)$ & $83(22)$ \\
Fairly Knowledgeable & $27(36)$ & $141(45)$ & $168(43)$ \\
Poor Knowledge & $8(11)$ & $129(41)$ & $137(35)$ \\
\hline Total & $74(100)$ & $314(100)$ & $388(100)$ \\
\hline
\end{tabular}

Likewise the attitudes of respondents towards adolescents' sexuality and communication practice were associated. The difference in having a negative attitude between parents/ caretakers that discussed and those that did not discuss was statistically significant $(p<0.05)$ for four statements $(4,5,6$ and 7 ) as shown in Table 3. 
The findings on communication means and methods (stories, examples, riddles, tales or jokes) among respondents $(19 \%)$ that discussed sexual matters with adolescents showed that minority $(9 \%)$ used verbal with written means and communication methods. Three quarters of respondents were unsatisfied with the methods they had used. Furthermore, only $5 \%$ of the respondents lacked information and educational materials related to reproductive health to give their adolescent children for reading.

The respondents' main source of sexuality information was the radio $(52 \%)$ and $14 \%$ felt that information obtained from the radio was adequate. Besides, there were no specific adolescent reproductive health services offered in the community.

Regarding family size and communication practice of respondents, the association was not statistically significant $(p=0.68)$. Findings on family composition specifically marital status showed that $74 \%$ of married/ cohabited respondents discussed sexual matters compared to other marital statuses and the difference was statistically significant $(\mathrm{p}=0.001)$.

Table 3 Attitudes of respondents on adolescent sexuality matters $(\mathrm{N}=388)$

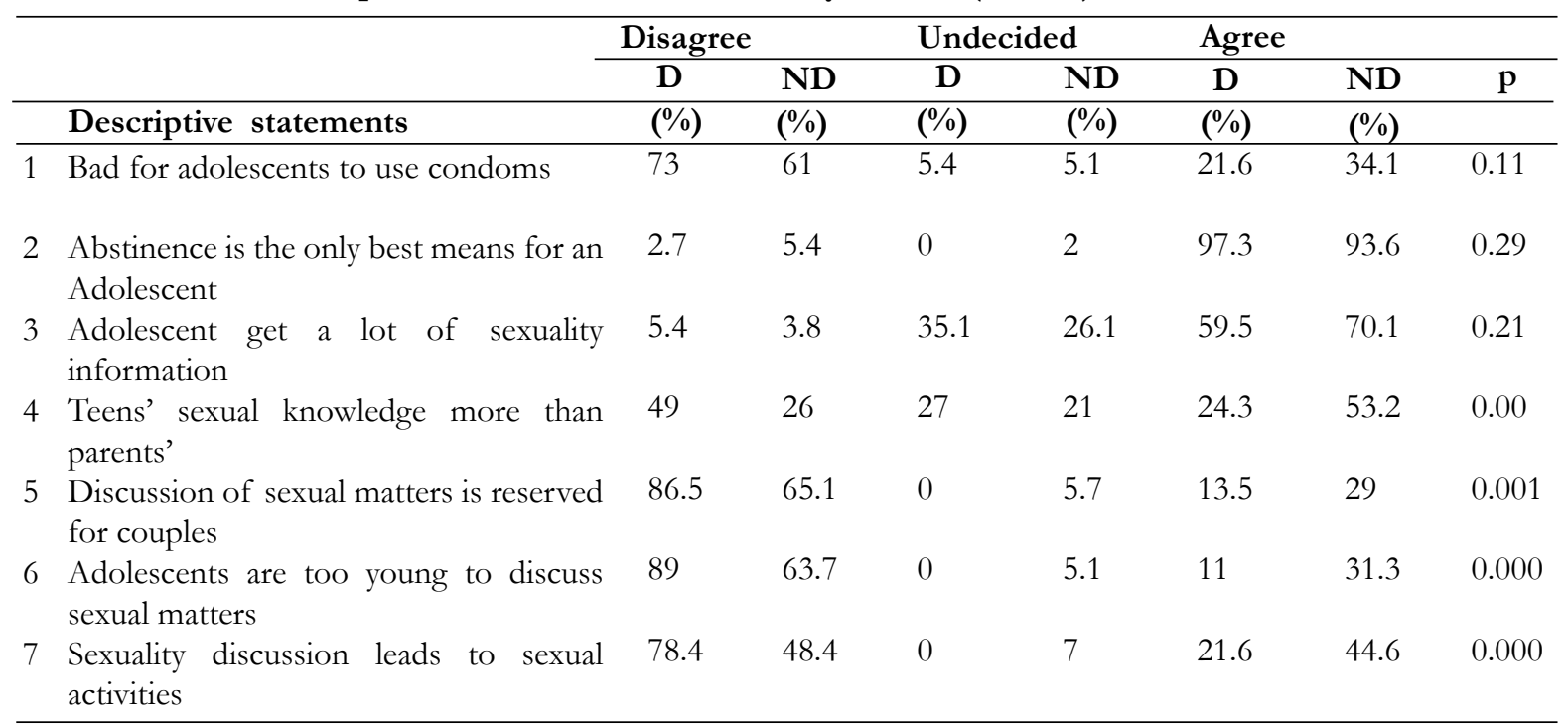

$\mathbf{D}$ is the Propotion of parents/caretakers that discussed sexual matters with adolescents.

ND is the proportion of parents/caretakers that did not discuss sexual matters with adolescents

\section{Discussion}

This study provides evidence that socio-demographic, individual and socio-environmental factors hindered parents from communicating sexual matters with the adolescents. Lack of communication among young parents/caretakers was attributed to less experience on discussions of sexual topics with adolescents, coupled with the sensitive nature of the topic. On the other hand, the elderly were reluctant to discuss with adolescents, young age of adolescent being a hindrance. These findings concur with previous studies $[17,18]$, where older parents were more conservative to give sex education to adolescents and elderly mothers were reported to have slightly lower frequencies of sexuality communication with daughters. The elderly parents/ caretakers might be strongly attached to cultural beliefs which inhibit them from holding discussions on sexual matters with adolescents. Nonetheless, some previous studies have yielded inconsistent findings about parental age and association to sexuality communication. [19]

Fewer male respondents compared to females discussed sexual matters with adolescents and this corroborates studies in USA and Argentina where mothers discussed sexual matters more frequently with their children than fathers. $[13,14]$ This difference between male and female communication practice could be due to the closeness with children in favor of mothers than fathers, which is similar to previous studies. $[19,20]$ Nevertheless, it is important to pass sexuality information to the boys as well.

Education level of respondents was another factor and majority that did not discuss sexual matters with the adolescents had education levels below secondary school. This supports previous study [21] where parents that had attained high level of education were more likely to discuss with adolescents sex-related topics. Thus parents/ caretakers with less or without formal education lack factual information about sexual matters and probably attach little importance on the benefits of parent-adolescent sexuality communication. However, findings also showed that over a half $(54 \%)$ of respondents above secondary-level education did not discuss with adolescents due to socio-cultural factors. This is similar to past studies that found no relationship between education level of parents and communication practice. $[11,22]$

This study also revealed that the association of religion to parents'/caretakers' communication practice was not statistically significant $(\mathrm{p}=0.06)$. This is similar to previous studies [19], where the association of religion to mothers' communication practice was not statistically significant $(\mathrm{p}=0.058)$. Furthermore, all 18 respondents without a 
religious affiliation did not discuss sexual matters with adolescents. Probably, some people affiliated to religion are inspired to discuss some sexual topics with adolescents, since religion teaches morality. Findings from the present study also showed some respondents that were inhibited from discussing sexual matters with adolescents due to religious beliefs. This supports previous findings [11, 23], where parents did not communicate with adolescents sexual matters due to religious beliefs.

The respondents' sources of income influenced communication with adolescents. Majority that relied on subsistence farming, a low source of income, did not communicate with adolescents. This is in tandem with previous findings [21] where respondents with high income discussed often sex-related topics with adolescents. Parents/ caretakers with low income find it difficult to access radio, TV and print materials for sexuality information. They are also likely to be less close to their children which curtails the communication process. These findings confirm a previous study [24], where parents appeared less available to adolescents compared to peers. Nevertheless, lack of sexuality communication between parents and adolescents has also been reported in families with good socio-economic status suggesting other underlying factors. [22]

Cultural factors inhibited parents/caretakers from discussing sexual matters with adolescents since the sexual topics were considered culturally sensitive. This corroborates several studies where cultural taboos have persisted and inhibit parents from discussing sexual matters with their children. $[10,11,20]$ Cultural beliefs and taboos about sexuality are deeply rooted in peoples' lives and hinder communication. Additionally, the use of Kinyarwanda for sexual terms was found a barrier to communication hence many health communicators recommend the use of traditional channels such as stories as an acceptable way of introducing sensitive topics. [25-26]

Lack of knowledge about sexual matters inhibited parents/caretakers (88\%) from discussing sexual matters with adolescents. This is congruent with previous studies $[1,8,9,20,27]$, where parents' lack of knowledge about sexual matters hindered communication. Lack of knowledge as a communication barrier [28, 29] makes an individual less confident or skeptical to talk about sexual topics and respond to the concerns raised by children. Respondents that either discussed or did not discuss also had negative attitudes towards adolescents' sexuality such as perception of abstinence as the best means for sexually active adolescents. This supports previous findings [21] where parents discussed frequently with adolescents about abstinence than contraception yet abstinence only is ineffective. Thus, the UNFPA [30] recommends propagation of abstinence messages alongside regular condom use. Respondents were also of the opinion that adolescents get sexuality information from teachers, radio and peers, hence they were informed about sexual matters. This is similar to previous findings [19] and such negative attitude diminishes the parents' role of communication which is relegated to other sources, which are too characterized by information gaps. $[1,8,31]$
Regarding communication approaches used by parents, almost all respondents reported a difficulty in the means to deliver sexuality messages to adolescents. This concurs with a previous study [20], where it is stated that: "When it comes to talking about sex, Latino parents don't know what to say, how to say it, or when to start'. The approach of delivering messages is one aspect of communication skills and lack of such skill affects negatively the transmission and exchange of sexuality messages with adolescents. Probably, this is the reason why many parents/caretakers gave warnings related to opposite sex relationships to their children, without holding discussions with them. Similar findings [15] were reported in Tanzania, where mothers said that their limited communication skills forced them to give instructions to adolescents rather than interacting with them.

Parents/caretakers also used mainly verbal means during talks with their children, yet verbal means only is not effective in information transmission and retention. Still, the parents/ caretakers did not organize any meeting for discussion or plan how or when to discuss with the children. This is in tandem with a previous study [15] where parents discussed with their children sporadically without deliberate plans. Meetings are interpersonal channels of communication and if they are regularly scheduled, communication between parents and children could be improved. Therefore, lack of meetings for discussions, giving warnings and use of verbal means describe the didactic method of communication which does not enhance effective communication between the parents and adolescents. [10]

Socio-environmental factors such as family size did not influence the respondents' communication practice $(\mathrm{p}=0.68)$. This needs to be investigated further since previous studies show that lower family sizes $(<5$ people) were positively associated with free discussion on sexual matters between parents and adolescent. [32] Regarding family composition, majority of respondents $(74 \%)$ that were married/ cohabited discussed sexual matters with adolescents. This could be due to the dual responsibility of parents in taking care of their children including the communication role. However, it was not possible to locate relevant literature against which to validate and contrast this finding.

The radio as the main source of information to parents/ caretakers shows that access to sexuality information through mass media is limited. This corroborates other findings [26] where it was reported that the mass media channels are not widespread in rural areas, despite their usefulness for sexuality information to parents and adolescents. Besides, having a radio as one major source of sexuality information is not adequate since people have different listening habits. That is why a variety of Information- Education-Communication methods are invariably used in health communication. [25, $28,29]$ There are also no activities in the community to promote parent-adolescent sexuality communication. This implies that parents are not adequately informed about the importance of such communication strategy and this could limit their opportunities to improve their knowledge about sexuality or change some negative attitudes that do not favor parent-adolescent communication. 
The results of this study implies that adolescents are poorly informed and lack information about sexual matters from their parents/caretakers, hence this puts them at high risk to contract STDs, HIV/AIDS or unwanted pregnancies and consequences such as abortion and school dropout.

\section{Limitations}

While this study has brought into insight the hindrances to parent-adolescent sexuality communication, there are limitations. First, the study used cross-sectional design thus implications about causality cannot be drawn. Secondly, purposeful sample was used at certain stage hence the findings cannot be generalized to other districts. Finally, the measure of communication was generalised and did not look into the length and depth of discussions. Furthermore, other factors like parenting style and behaviours were not considered which influence sexuality communication. Nevertheless, the study has shed light on the constraints to parent- adolescent communication about sexual matters.

\section{Conclusions}

Majority of respondents (81\%) did not discuss sexual matters with the adolescents and those that discussed used mainly verbal means, very few communication methods and often gave warnings to their children. This is unidirectional communication which does not enhance effective transmission of sexuality messages. Therefore, adolescents continue to lack information from parents/caretakers which otherwise could have empowered them to make informed decisions about their sexual and reproductive health needs.

The major factors that hindered parent-adolescent communication were lack of knowledge about sexual matters and limited communication skills in providing information to the adolescents. Furthermore, parents/ caretakers had limited access to sexuality information which could perpetuate beliefs, taboos and negative attitudes that hindered them from discussing sexual matters with adolescents.

The age and gender of parents/caretakers was found associated with communication practice.

Parents/caretakers $(83 \%)$ had positive attitudes in having sexuality information passed to their children. Given guidance on sex education principles, parents/caretakers could initiate or improve discussions about sexual matters with adolescents.

\section{Recommendations}

Sensitization campaigns about parent-adolescent communication should be strengthened and messages disseminated to guide parents on how to introduce or approach the subject of sexuality to the adolescents.

In designing messages targeting parents/caretakers to communicate sexual matters with adolescents, their sociodemographic characteristics should be put into consideration. The parents/caretakers in the study area were pre-occupied with routine work for a living but they should spare time for discussion of sexual matters with adolescents.
Research should be conducted on the knowledge, attitudes and practices of adolescents as far as sexuality is concerned. This will help in designing tailored communication strategies to inform adolescents and parents about sexual matters.

\section{Acknowledgements and funding}

I extend special thanks to various teachers and village leaders in Mukarange sector without whom data collection would not have been possible. Many thanks go to the community members who provided the information needed and availed their children to participate in the study. I also appreciate the support of the Ministry of Education, Rwanda, for providing the funds to conduct the study.

\section{Conflict of interest}

The author declare that there is no conflict of interest.

\section{Authors' contribution}

I acknowledge the authors' contribution to this piece of work particularly guidance on stating the study objectives and organizing literature (O.R) designing conceptual and theoretical frameworks (A.B), qualitative (O.R) and quantitative (A.B) data analysis and presentation. I also appreciate the staff of the University of Rwanda for the inputs in preparing the manuscript, organizing the methodology (S. F X), proof reading and editing (A.D).

\section{References}

1. United Nations Population Fund. Lives together, worlds apart; Men and Women in a time of change. Geneva: UNFPA; 2000

2. Ogle S, Glasier A, Riley SC. Communication between parents and their children about sexual health: Contraception 2008; 77(4): 83-88.

3. Biddlecom A, Awusabo-Asare K, Akinrinola B. Role of Parents in adolescent sexual activity and contraceptive use in four African countries. International perspectives on sexual and reproductive health 2009, 35 (2). http:// www.guttmacher.org/pubs/journals(accessed 20 May 2010).

4. Kimberlee S S. Factors that contribute to, and constrain conversations between Adolescent Females and their mothers about sexual matters. Forum on Public Policy 2006. www.forumonpublicpolicy.com/archive06/ schear.pdf. (accessed 26 May, 2010).

5. URUNANA Development communication. http:// www. urunanadc.org (accessed 10 May, 2011).

6. IMBUTO Foundation. http://imbutofoundation.org/spip. php?article1(accessed 5 April 2011)

7. Twahirwa A. Efforts to contain HIV/AIDS among teens Slacken. Inter press service agency. http:/ ipsnews. net/news.asp?idnews $=503152010$ (accessed 10 June 2010). 
8. Opia M K. The media and youth in Sub Saharan Africa, towards a partnership for population in development. Ethiopia, UNFPA country support team, CSTAA Technical Paper report, number: 4, 1999

9. Aggleton P, Warwick. Young People, Sexuality, HIV and AIDS. Amsterdam, Netherlands: Hard wood academic publishers, 2006

10. Botchway. Parent and adolescent male's communication about sexuality in the context of HIV/AIDS. MPhil thesis (Unpub), University of Bergen;2004

11. Mbugua N. Factors inhibiting educated mothers in Kenya from giving meaningful sex-education to their daughters. Social Science \& Medicine, 2007; 64: 1079_ 108. wnw.elsevier.com/locate/socscime 1079-1089, (accessed 19 October 2010)

12. Diiorio C, Kelley M, Hockenberry-Eaton. Communication about Sexual Issues: Mothers, Fathers, and Friends. Journal of Adolescent Health, 1999; 24 (3):181-189. http:/ / wnw. Linking hub. elsevier.com (accessed 15 December 2009).

13. Brown A D, Shireen J, Jejeebhoy, Iqbal S, Kathryn M, Yount K. Sexual relations among young people in developing countries,Evidence from WHO case Studies. Department of Reproductive Health and Research Family and Community Health,World Health Organization,Geneva. Paper number: 4, 2001, bttp:// www.heart-intl.net/heart $/ 110105$ (accessed 20 March 2010).

14. Mendez D A. Behaviours of female adolescents at high risk of HIV or other STDs. American journal of Public Health, 2005, 25 (4): 1045

15. Namisi F S, Flisher A J, Overland S, Bastien S, Onya H.,Kaaya S, Edvard Aarø E L. Socio-demographic Variations in Communication on Sexuality and HIV/ AIDS with parents, family members and teachers among in-school adolescents, A multi-site study in Tanzania and South Africa. Scandinavian Journal of Public Health, 2009; 37(2): 65-74.

16. Cochran W G. (1977) Sampling Techniques (Third Ed). Wiley.

17. Coreil J, Parcel G S. Socio-cultural determinants of parental involvement in sex education. Journal of Sex Education and Therapy, 1983; 9(2):22-25.

18. Jaccard J. Sexual Communication, Couple Relationships, Parent-child Relationships. 2010, http:/ / family.jrank.org/ pages/1501/Sexual-Communication.html (accessed 15 May 2010)

19. Pluhar E I, Dilorio C K, McCarty F. Correlates of sexuality communication among mothers and 6-12-yearold children. 2007, http://wmw3.interscience. wiley.comcgibin/fulltext/119402697 (accessed 8 July 2010).
20. Guilamo-Ramos V, Bouris A. Parent-Adolescent Communication about Sex in Latino Families. A Guide for Practitioners, 2008

21. Lefkowitz E S, Boone T L, Terry Kit-fong T, Sigman M. No sex or safe sex? Mothers' and adolescents' discussions about sexuality and AIDS/HIV. 2001. http:/ / her.oxfordjournals org / cgi / content/ full (accessed 7 July 7, 2010)

22. World Health Organization. What about boys? A literature review on bealth and development of adolescent boys. Department of child and adolescent health and development, Geneva, 2000

23. Mpairwe A. Factors affecting Parent-Child Communication on issues of sexual and reproductive health. MPH Thesis (Un pub), Makerere University; 2007

24. Olayo R N, Kaseje C. Characteristics of information sources that influence sexual behaviour among in school adolescents. A case study of a peri-urban setting, Nairobi. African journal of community bealth and development, 2009; 1(1) 7-9

25. Ministry of Health. National Behavior Change Communication Sector Policy, Rwanda, 2006

26. Odek T. Cultural Challenges and Sex Education in Mageta Islands. Post-Sexuality Leadership Development Fellowship. Report series number: 3, 2006.

27. Beringer L H, Eisenberg M E, Sieving R E, Swain C, Resnick M D. Parents' beliefs about condoms and oral contraceptives; Are they medically accurate? "Perspectives on Sexual and Reproductive Health. 2004; 36: 50-57, wmw.forumonpublicpolicy.com/ archive 06/ schear. $p d f$ (accessed 26 May 2010)

28. Hubley J. Communicating Health: An action guide to bealth education and bealth promotion, London. Macmillan education ltd, 1995

29. Maurer F, Smith C M. Community public health nursing practice; Health for families and populations, Canada: Elsevier Saunders, 2005

30. United Nations Population Fund. Prevention HIV in young people: HIV prevention now. Geneva, population issues 2008. wmw.unfpa.org./aids/prevention/doc (accessed10 January 2010)

31. Johns Hopkins University. Youth and HIV/AIDS Population Information program, Baltimore. Population report: Number 3, 2001

32. Negussie T, Rahel H, Selamu D, Alemayehu T, Kedir M. Do parents and young people communicate on sexual matters? The situation of Family Life Education in a rural town of Ethiopia. Ethiopian Journal of Health development, 1999; 13(3):205-210 